\title{
Anna Maria Guasch
}

\section{LA MEMORIA DEL OTRO EN LA ERA DE LO GLOBAL}

A pesar de lo negativo de los procesos de homogeneización que genera, la globalización, al decir de Arjun Appadurai, es una "máquina” o una "tecnología” que colabora a ampliar nuestros horizontes aportando rutas para conectarnos con otras sociedades, otras gentes, otros pensamientos, no sólo a través de los media tradicionales o de las mediaciones electrónicas sino de lo que Appadurai llama "experiencias mediadas", desde la del viaje y la migración hasta las derivadas del diálogo, es decir, las "experiencias dialógicas"1. La globalización, deja de ser entonces un proceso externo abstracto, distante, que cambia constantemente de coordenadas e incluso puede generar pánico, y se convierte en un vehiculo - con componentes utópicos, ciertamente- que agranda y proyecta las expectativas y las aspiraciones locales. Es bajo este punto de vista, el de concebir la globalización no como un proceso a gran escala, sino de "producción de localidad", la localidad de las "nuevas minorías" planteadas por Appadurai, como entendemos esta proposición, más que exposición, sobre la memoria y la otredad, una otredad identitaria de la conflictiva vida cotidiana en el sentido social e individual, pero no aislada ni tan siquiera singular ni menos exótica ya que está conectada y, a la vez, es parte y consecuencia de las redes globales.

\footnotetext{
${ }^{1}$ Arjun Appadurai,"Minorities and the Production of Daily Pace. Interview with Arjun Appadurai", en Joke Brouwer y Arjen Mulder, eds., Feelings are Always Local, Rotterdam, NAI Publishers, 2004.
} 


\section{Exposiciones identitarias}

La Documenta 11 de Kassel (2002), comisariada por Okwui Enwezor, supuso un turning point en el sentido de que el arte de la periferia, según la visión hegemónica occidental, del "otrora otro" se "instaló" en el supuesto centro del escenario cultural. Inauguró las llamadas "exposiciones identitarias" (como la que proponemos) y supuso un importante cambio de paradigma artístico al declarar no sólo la centralidad de lo poscolonial, sino de lo local marcando distancias con las políticas identitarias asociadas al anti-universalismo posmoderno y a su relativismo. Okwui Enwezor asumió una nueva filosofía curatorial en sintonía con el concepto de globalización y con las tesis del Empire de Hard y Negri², una filosofía interesada no sólo en temáticas relativas al arte, sino a la cultura y a la economía; economía y cultura en tanto síntomas de nuevos tiempos o lo que Gilles Lipovetsky denomina la cultura-mundo, la cultura del tecno-capitalismo que asume una vocación planetaria e invade todos los sectores de la sociedad. Como sostiene Lipovetsky, ya no más el cosmos fijo de la unidad, del sentido último, de las clasificaciones jerarquizadas, sino el de las redes, de los flujos sin límite ni centro de referencia:

En los tiempos hipermodernos - afirma el filósofo francés-, la cultura se ha convertido en un mundo en el cual la circunferencia está en todas partes y el centro en ninguna ${ }^{3}$.

Una cultura-mundo en la que lo "universal humanista" cede su protagonismo a lo "universal concreto y social” y en la que la economía-mundo se agencia según un modelo único de normas, de valores, de fines: el ethos y el sistema tecnocapitalista. Una cultura-mundo que asume cuestiones y problemas de dimensiones "globales" como la ecología, la crisis económica, la inmigración, la pobreza y el terrorismo, pero también cuestiones de carácter existencial, como la identidad, las creencias y las crisis de sentido, o los problemas de personalidad: mundo, en definitiva, que se convierte en cultura, cultura que se convierte en mundo, como asevera Lipovetsky. Una cultura-mundo sin fronteras territoriales, económicas o políticas que desborda en todos sus principios los límites de las culturas derivadas del Humanismo clásico. Una cultura-mundo que no es ni

\footnotetext{
${ }^{2}$ Michael Hart y Antonio Negri, Empire, Cambridge, Mass., Harvard University Press, 2000.

${ }^{3}$ Gilles Lipovetsky y Jean Serroy, La Culture-monde. Réponse à une société désorientée, París, Odile Jacob, 2008, p. 8.
} 
espejo ni reflejo de las sociedades, sino el principio que las engendra, las constituye, las modela y las hace evolucionar. Se han abandonado -o se deberían haber abandonado - las oposiciones binarias del tipo alta/baja cultura, cultura antropológica/cultura estética, cultura material/cultura ideológica, y se han liberado las estructuras elementales y los polos de la cultura-mundo que fertilizan desde la cultura tecno-científica hasta la cultura del individuo, pasando por la cultura mediática y la cultura de redes, estructuras y polos que han generado- o viceversa- un nuevo tipo de creador/recreador/manipulador/comunicador de imágenes al que continuamos llamando, por inercia o por no haber encontrado nombre alternativo, artista.

En Documenta $11^{4}$ emergió ese "otro artista" habitante del mundo global y participante en ese micromundo que se nuestra en La Memoria del Otro: un artista interesado en el discurso social -no de clases sino de territorios-, no tanto creador de imágenes sino investigador de ellas, que reúne, crea, cuestiona, relata y expone información icónica o de otro tipo sobre temas de carácter universal, en tanto que individual o socialmente locales, en un formato que la sociedad occidental o del "nosotros" ha tipificado y ratificado como "arte". Un artista que utiliza esa información no como "único objeto" de análisis, sino como un instrumento más, pero privilegiado en su estatus "en tanto que arte", para desenmascarar, descubrir, denunciar, analizar... aspectos censurados, humillados, violentados o heridos del mundo actual: democracia, justicia, otredad, migración, desarraigo, diáspora... Temas que poco o nada tienen que ver con las "formas-devida", sino con la vida sacrificable desalojada del mundo, reducida a la supervivencia, la nuda vida que Giorgio Agamben plantea en su "teoría de la marginalización" 5 , una vida a expulsada a los márgenes de lo social, inmisericorde en lo político, en lo jurídico y en lo biológico; una vida que aliena, cuando no elimina, a los ciudadanos, que les priva de sus derechos como tales, que les abandona en el fango de los corruptos sistemas jurídicos, que convierte el ser humano, como plantea Agamben, en un homo sacer, en un deportado de cualquier orden y de cualquier beneficio de la sociedad, abandonado a inexistentes "dioses", y que con su sola presencia "mancha" a la sociedad.

\footnotetext{
${ }^{4}$ Okwui Enwezor, “The Black Box", en Documenta 11_Platform 5: Exhibition, Ostfildern-Ruit, Hatje Cantz Publishers, 2002, p. 45.

${ }^{5}$ Giorgio Agamben, Homo sacer. El poder soberano y la vida nuda, Valencia, Pre-Textos, 1998.
} 
Ese homo sacer de nuda vida, sin dioses a los que invocar, es el que, paradójicamente ha robado la presencia cuando no el papel principal a los dioses, a los emperadores, a los nobles, a los burgueses o a los revolucionarios que sucesivamente y a lo largo de siglos han sido los protagonistas del arte ${ }^{6}$ tal como podemos constatar en esta proposición/exposición. Los trabajos que en ella se presentan, más que utilizar el arte como protesta, propaganda o agitprop se plantean desde la dimensión ético-política que descubre lo recluido de los derechos humanos y lo expandido de lo excluido, abandonado y reprimido, el mundo enlodado de la nuda vida y el de las zonas de indistinción en las que el poder se convierte en control o en terror. Pero todo ello, sin renunciar- no sería justo hacerlo puesto que supondría envilecer lo que ya se ha enlodado- lo estético, en un sentido que está próximo tanto a la "estética política" de Agamben como a lo estético de Jacques Rancière cuando formula la conformación de lo sensible en el ámbito de las nuevas relaciones entre política y estética. Es en el terreno estético, entendiendo por estética no la teoría del arte en general enraizada en la perspectiva hegeliana, sino un determinado régimen de pensamiento que articula las maneras de hacer - y de ser- y las formas de visibilidad, sostiene Rancière, en donde hoy se puede producir la batalla. Una batalla que en otro momento hacía referencia a las promesas de emancipación y a las ilusiones y desilusiones de la historia, y que ahora va más allá de los debates de la autonomía del arte y de su sumisión política, eliminando el control de lo que se ve y lo que se puede ver, y el hiato entre los que tienen competencia para ver y calidad para decir y a los que no se les otorga ${ }^{7}$.

\section{Imagen móvil}

En La Memoria del Otro, el artista representa o presenta esas zonas de incertidumbre o indistinción a través de tecnologías de la imagen móvil, que le permiten trabajar en los intersticios que se abren en los campos de la

\footnotetext{
${ }^{6}$ Véase al respecto Anthony Downey, “Zones of Indistinction. Giorgio Agamben’s Bare Life and the Politics of Aesthetics, en Third Text, vol. 23, n² 2, marzo 209, p. 110.

${ }^{7}$ Jacques Rancière, La división de lo sensible. Estética y política, (2000), Salamanca, Centro de Arte de Salamanca, 2002, p. 28.
} 
documentación y el arte, tal como expuso Borys Groys en el texto "Art as Documentation", al exponer la documentación como un método para el arte contemporáneo, una documentación que no se estanca en los métodos aparentemente objetivos del documental sino que adopta sin complejos los formatos de la interpretación al hacer explícito el papel del artista en la selección, manipulación, síntesis y descodificación de la información hasta lograr la emergencia del autor desvinculado del sujeto autobiográfico. Un sujeto que, disconforme y contrario a la manipulación pública o corporativa de la información, se sirve de la potencia de las imágenes del mundo global (algunas propias, otras ajenas o apropiadas de medios como televisión, cine, internet) para coleccionar, procesar, interpretar y diseminar información a la comunidad'. Es ahí donde cobra sentido la utilización del film y del video como instrumentos y medios creativos, que si bien ya habían sido ampliamente empleados en las dos últimas décadas del siglo XX, aquí, en La Memoria del Otro, adquieren una nueva instrumentalización al evidenciar una dimensión subjetiva derivada de los encuentros individuales y empíricos de cada artista con la geografía en tanto que espacio social e identitario y de los procesos de desplazamiento en un mundo diaspórico e inestable. Factor el de lo empírico, entendiendo la experiencia como un "encuentro directo" que posibilita una "historia desde atrás", una "historia oral" o una "historia del día a día" que halla su sustento en lo etnográfico y no en una percepción abstracta derivada de grandes momentos y figuras, historia que, como plantean Irit Rogoff y Martin $\mathrm{Jay}^{10}$, asegura la autenticidad de conocimiento derivada de la "proximidad" con lo real.

Junto al film o al video, en tanto que ficción, interacción en vivo, performance o tableaux vivants, La Memoria del Otro presenta otros métodos de trabajar con la imagen móvil y, en particular, la imagen concebida como un "flash" de la memoria- más sincrónico y espacial que diacrónico y temporal- o "índice" del interés por lo doméstico y por el espacio familiar que hace asomar problemas de

\footnotetext{
${ }^{8}$ Boris Groys, “Art and Documentation”, en Documenta 11_Platform 5: Exhibition, op. cit.

${ }^{9}$ Angela Dimitrakaki, "All that is solid melts into air but I can't change anything. On the identity of the Artist in the Networks o Global Capital”, en Jonathan Harris (ed.), Identity Theft. The Cultural Colonization of Contemporary Art, Liverpool, Liverpool University Press, Tate Liverpool, p. 2008, p.231.

${ }^{10}$ Irit Rogoff, "De-Regulation: With the work of Kultug Ataman", en Third Text, vol. 23, n 2, 2009, pp. 175-176. Véase también Martin Jay, Songs of Experience, Berkeley, University of California Press, 2005.
} 
diferencia, identidad, raza y etnicidad. Pero hay que tener en cuenta que esta utilización del video como documentación subjetiva, en la que el "yo" del artistainvestigador-ensayista (siempre fragmentado) aparece en primera persona en sus diálogos con el "otro", no implica un renovado culto al "ego" de referencia romántica, sino un activo compromiso con el mundo y con la historia concebida como un "archivo horizontal" en el que conviven sin jerarquías una multiplicidad de destellos que proyectan a narrativas locales en el marco de las múltiples "geografías del capital", y lo hacen en constante negociación con los criterios estéticos en términos de estrategias políticas, sin eludir, no obstante, las relaciones simbólicas.

\section{El "efecto memoria": memoria, historia, etnografia}

Para acercarnos al argumento de la memoria o al "efecto memoria" ${ }^{11}$, hay que considerar que en el arte actual la memoria se ha convertido tanto en una preocupación histórica, como en un problema artístico y teórico, y que ello ha propiciado lo que se ha llamado el "giro memorialista" u obsesión por la memoria, tanto de la memoria instintiva (mnemé o anamnesis) como de la memoria como consignación o almacenamiento (hypómnema), tanto de la memoria individual como de la colectiva o cultural. Por otra parte, tal como señalan Pierre Nora y Andreas Huyssen, las obras de arte pueden ser consideradas "repositorios de memoria" o lugares de memoria, dando por supuesto que las memorias y las historias que aparecen en ellas, representadas o sugeridas, pertenecen a diferentes contextos y latitudes, a un tiempo y un lugar específico, a una "site specificity".

En la cuestión del "Memory Effect" se inscriben la totalidad de los artistas presentes en esta exposición, como Ursula Biemann, Hannah Collins, Francesco Jodice, Rogelio López Cuenca, Antoni Muntadas y Krzysztof Wodiczko, que coleccionan, recoleccionan y presentan a través de narraciones fracturadas imágenes e información de un mundo percibido como una base de datos transdisciplinar. Artistas que de alguna manera siguen el legado metodológico de Aby Warburg, quien en su proyecto Atlas Menmosyne (1927-1929) mostró el

\footnotetext{
${ }^{11}$ Charles Green, "The Memory Effect. Anachronism Time and Motion", en Third Text, vol. 22, no 6, noviembre 2008, pp. 681-697.
} 
"efecto memoria" subyacente al aliento temporal y espacial de la historia del arte occidental y no occidental a partir de una ecléctica, diversa y desigual colección o archivo de fragmentos visuales en el que cada imagen es un intervalo "fijo" pero cuya lectura final sólo se entiende a través del "montaje" de esos intervalos.

Esta perspectiva "transdisciplinar" de la memoria ha permitido que la etnografía y el culto por el presente y el interés por lo espacial (que en algún momento se entendieron como únicas reivindicaciones de la posmodernidad) resulten ahora ajenas a la cuestión del tiempo y de la memoria. En otras palabras, lo que se tenía como exclusivo de los intereses de la antropología : el estudio de los espacios habitados a través de categorías referidas a geografías, fronteras, rutas comerciales, migraciones, desplazamientos y diásporas, entre otras, se involucra con el análisis histórico con vocación universalista, vinculado con continuidades temporales y atento a la reconstrucción del pasado/presente.

Lo sincrónico (el modo horizontal de trabajar) y lo diacrónico (el modo vertical), ya no se perciben como categorías separadas e incluso antagónicas sino que, a partir de la zona intersticial que es la memoria y que interviene tanto en la historia como en el presente, se producen en "parallax”. En Tristes Trópicos (1955),Lévi Strauss ya planteó la estrecha relación entre la etnografía, producto del mapeo del territorio del trabajo de campo, de la observación participante, del inventariocrónica periodístico, del libro de confesiones... con la memoria y con el olvido, entre la "huella" o la "ruina” y el "recuerdo", posición que años después no sólo fue refrendada por David Harvey en La condición posmoderna (1989), sino por Andreas Huyssen, quien en Present Pasts. Urban Palimpsests and the Politics of Memory (2003) puso de manifiesto que el auge de los discursos de la memoria no sólo tenían que ver con el debate iniciado en la década de los ochenta sobre el Holocausto y su concepto de "memoria territorializada", sino con el desplazamiento hacia la memoria del "otro", en el que confluyen lo cartográfico (propio del pensamiento sincrónico) y lo memorialista (propio del pensamiento diacrónico).

Marc Augé da un paso más en este sentido y dibuja una situación etnológicosocial en relación a lo que denomina "tiempo puro", un tiempo sin fecha que no está presente en nuestro mundo de imágenes, simulacros, reconstituciones e 
historia. Definidos los "no lugares" de la sobremodernidad que acelera la historia, retrae el espacio e individualiza los destinos, es decir, los lugares no antropológicos que no pueden concebirse ni como espacios de identidad ni relacionales ni históricos, es momento de concretar los "lugares de la memoria" poblados de ruinas, de estratos desordenados de escombros y monumentos del pasado, los lugares de un "tiempo puro" y perdido, los lugares no corrompidos por la falsificación de la realidad que pretende convertir el lugar en bien de consumo, los lugares de la verdad y la vida cuya competencia atañe - como sostiene Augé- al arte.

Frente al antropólogo tradicional que, ante la cantera de la realidad que tenía ante sus ojos, intentaba construir un inventario de objetos perdidos a partir del cual elaborar las teorías interpretativas, las secuencias históricas y los episodios míticos, el "nuevo antropólogo" no trabaja con las ruinas como objetos inanimados o como esqueletos del pasado. Para él y para los artistas de La Memoria del Otro que desarrollan esta problemática, Ursula Biemann, Hannah Collins, Francesco Jodice, Rogelio López Cuenca, Antoni Muntadas y Krzysztof Wodiczko, contemplar y trabajar con las ruinas de la realidad, no supone emprender un viaje por la historia, sino vivir la experiencia del "tiempo puro" que, en definitiva, es tiempo del presente por no ser del pasado: "En su vertiente pasada, la historia es demasiado rica, múltiple y profunda para reducirse al signo de piedra que ha escapado de ella, objeto perdido como los que recuperan los arqueólogos que rebuscan en sus cortes espacio-temporales. En la vertiente presente del tiempo, la emoción es de orden estético, pero el espectáculo de la naturaleza se combina en esta vertiente con el de los vestigios"12. Los artistas de La Memoria del Otro de este ámbito, no sólo trabajan, analizan y comunican lo que tienen ante sus ojos : ciudades, campos avasallados, colonizadores, colonizados, potentados, hambrientos, indígenas, inmigrados, hombres, mujeres, ya que para ellos el "inventariar" los fragmentos ruinosos de la realidad no es un fin en sin mismo y ni tan siquiera un fin; lo que importa es la reinvención, la reconstrucción de la realidad: "La humanidad no está en ruinas. Está en obras -asiente Augé- Pertenece aún a la historia, una historia con frecuencia trágica, siempre desigual, pero

\footnotetext{
${ }^{12}$ Marc Augé, El tiempo en ruinas, Barcelona, Gedisa, 2003, pp. 18 y $45-46$.
} 
irremediablemente común"13. Es necesario volver a sentir el tiempo para tener conciencia de la historia:

En un momento en el que todo conspira para hacernos creer que la historia ha terminado y que el mundo es un espectáculo en el que se escenifica dicho fin, debemos volver a disponer de tiempo para creer en la historia. Ésta sería hoy la vocación pedagógica de las ruinas ${ }^{14}$.

\section{Traducción}

La negociación entre lo sincrónico y lo diacrónico, entre lo antropológico y lo histórico sólo se hace posible a través de otro componente esencial: el de la traducción, entendida como un instrumento para crear espacios de un entendimiento transversal, y como un concepto paradójico en tanto procura entendimiento al mismo tiempo que señala la potencialidad de lo no-traducible. Una traducción que no debe de entenderse como un medio o una función lingüística (como así ocurría en los textos lingüísticos y etnográficos de la década de los años treinta y cuarenta) sino como un instrumento cultural y político, un instrumento que no sólo permite la incorporación hegemónica del "otro", sino que muestra la potencialidad de resistencia en el proceso de traducción en sí mismo.

Si en el proceso colonial, la traducción interesaba especialmente por su capacidad de construir puentes entre culturas, por lo que era percibida como un acto fundamentalmente de comunicación, lo que ahora incumbe es plantear el "contexto" de la traducción. Entendida como el proceso de incorporar la voz de la diferencia, la traducción se basaría, recogiendo las reflexiones que Walter Benjamin aportara al respecto en su ensayo de 1923 "La tarea del traductor" (Die Aufgabe des Übersetzers) justamente en la imposibilidad de crear una "imagenespejo" del original debiéndose entender, como con posterioridad apuntó Derrida en uno de los ensayos La difference (1968) como un flujo, un movimiento transitorio que a través de sus dos polos produce un "suplemento". Un suplemento cuya función no sería otra que deconstruir las premisas en las que se

\footnotetext{
${ }^{13}$ Marc Augé, op. cit., p. 19.

${ }^{14}$ Marc Augé, op. cit., p. 53.
} 
basa culturalmente la traducción; un suplemento que no sería inteligible hasta la creación de un tercer término distinto del original y del traducido. El suplemento no es ni un más ni un menos, ni algo exterior ni el complemento de lo interior, ni un accidente, ni una esencia y en todos los casos suministra un espacio de un modelo cultural en dicotomía que apunta a la transgresión en el marco de un amplio encuentro entre diferentes interfaces de idiomas, maneras de hablar o entender el mundo ${ }^{15}$.

\section{Interculturalidad}

La cuestión de la traducción como una manera de capturar las "trazas" del otro (práctica común entre los artistas de La Memoria del Otro, sean por ejemplo Jodice, Muntadas o Wodiczko ) en uno mismo al trabajar alrededor de los "confines" del contexto en el que tienen lugar estos mismos trazos y de trabajar a través de la tensión entre diferencia e identidad, respetando la individualidad y originalidad de la presencia de la "otra voz", conduce hacia otra cuestión esencial en el arte de hoy y en la presente proposición/exposición: el de la situación dialógica. Algunas de las obras presentadas ( Biemann, Collins y López Cuenca) evidencian radicalmente que ya no son válidos algunos de los conceptos manejados habitualmente en el campo de las estratificaciones sociales y culturales. No es válido el paradigma de la cultura poscolonial, especialmente occidental, que examina la cultura de los "otros" con términos- que son conceptos- como los de "segundo" y "tercer" mundo, ni es válido el paradigma occidental concerniente a la formación de identidad en el propio territorio occidental. Son paradigmas unidireccionales que deben ser, y así lo ha interpretado y ejercido el arte, como procesos bilaterales que afectan tanto - y permítasenos utilizar paradójicamente las expresiones- a "colonizadores" como a "colonizados".

En el ámbito de este bilateralismo de base, cobra todo su sentido el diálogo entre culturas que plantea una relación del tipo "yo/tú-tú/yo" en la que cada una de las partes reconoce en el otro a una "persona", es decir, a un "fin" en sí mismo y no a un "medio" para conseguir un objetivo. Un diálogo que permite superar la fase del

\footnotetext{
${ }^{15}$ Jacques Derrida, "La différance" (1968), ensayo incluido en Marges de la philosophie, París, Éditions de Minuit, 1972.
} 
multiculturalismo por la filosofía política del "interculturalismo", es decir, la del intercambio cultural a través de procesos inter-nacionales, con lo que ello supone de nueva reapropiación crítica de lo nacional. Se tiene que avanzar pues hacia lo "intercultural" que supera la antigua dicotomía identidad/diferencia y hacia los diálogos entre distintos contextos nacionales a través de una mayor potenciación de las subjetividades, es decir, de las realidades particulares de cada ser humano más allá del concepto de lo "étnico", y de un intenso y productivo diálogo entre lo universal y lo local, entendiendo lo local más en su sentido relacional y contextual que escalar o espacial.

De un modo distinto al multiculturalista el cual se distanciaría a sí mismo del "otro" a través de una privilegiada universalidad, el interculturalista elimina las distinciones en aras de una universalidad compartida: "Todos somos universales o nadie lo somos"; "Todos somos exóticos o nadie lo somos". En el espacio vacío del encuentro intercultural, desaparece lo étnico a favor de la identidad humana universal, de sus creatividades y de sus potencialidades.

Como sostiene el filósofo y escritor iraní Ramin Jahanbegloo cada cultura se descubre en los otros y viceversa, al percibir simultáneamente las similitudes y diferencias. El diálogo con el otro, como se ha pretendido presentar en esta proposición/exposición es un diálogo con uno mismo. $\mathrm{Y}$ es así como cada cultura ve a la otra como un "acontecimiento" y como una "puerta abierta". La presencia de una cultura diferente es esencial para crear y garantizar posibilidades nuevas ${ }^{16}$.

\footnotetext{
${ }^{16}$ Ramin Jahanbegloo, Celebrating Diversity, http://www.india-seminar.com/2007/569/ 569_ramin_jahanbegloo.htm
} 